\title{
FE DE ERRATA
}

Correa-Sandoval, A., Rodríguez-Castro, R., Venegas-Barrera, C. S., Horta-Vega, J. V., Barrientos-Lozano, L. y Rodríguez- Castro, J. H. (2017). Diversidad y zoogeografía de los moluscos terrestres de la sierra de Tamaulipas, México. Acta Zoológica Mexicana (n.s.), 33(1), pág. 85 .

\section{APÉNDICE 1}

\section{Localidades visitadas en la Sierra de Tamaulipas}

\begin{tabular}{|c|c|c|c|}
\hline \multirow[b]{2}{*}{1} & \multirow{2}{*}{$\begin{array}{c}\text { Localidad } \\
\text { Km 52. Carretera Victoria - Soto La Marina después de Villa de Casas }\end{array}$} & \multicolumn{2}{|c|}{ Coordenadas geográficas } \\
\hline & & $23^{\circ} 39^{\prime} 83^{\prime \prime}$ & $98^{\circ} 39^{\prime} 42^{\prime \prime}$ \\
\hline 2 & Km 64 Carretera Victoria - Soto La Marina & $23^{\circ} 34^{\prime} 99^{\prime \prime}$ & $98^{\circ} 36^{\prime} 15^{\prime \prime}$ \\
\hline 4 & Km 64.5 Carretera Victoria - Soto La Marina, después de El Pirulí & $23^{\circ} 34^{\prime} 37^{\prime \prime}$ & $98^{\circ} 31^{\prime} 29^{\prime \prime}$ \\
\hline 5 & Km 74 Carretera Victoria - Soto La Marina, antes de El Sabinito & $23^{\circ} 34^{\prime} 30^{\prime \prime}$ & $98^{\circ} 30^{\prime} 81^{\prime \prime}$ \\
\hline 6 & Km 115 Carretera Victoria - Soto La Marina & $23^{\circ} 43^{\prime} 56^{\prime \prime}$ & $98^{\circ} 13^{\prime} 62^{\prime \prime}$ \\
\hline 8 & Rancho La Palma, Carretera Victoria - Soto La Marina, lado izquierdo de la carretera & $23^{\circ} 34^{\prime} 36^{\prime \prime}$ & $98^{\circ} 29^{\prime} 77^{\prime \prime}$ \\
\hline 9 & Rancho La Palma Carretera Victoria - Soto La Marina, lado derecho de la carretera & $23^{\circ} 34^{\prime} 30^{\prime \prime}$ & $98^{\circ} 29^{\prime} 43^{\prime \prime}$ \\
\hline 10 & Carretera La Pesca - Soto La Marina, después de Vista Hermosa & $23^{\circ} 48^{\prime} 98^{\prime \prime}$ & $97^{\circ} 55^{\prime} 52^{\prime}$ \\
\hline 11 & Carretera La Pesca - Soto La Marina, antes de la desviación al Chapote & $23^{\circ} 44^{\prime} 94^{\prime \prime}$ & $97^{\circ} 55^{\prime} 57^{\prime \prime}$ \\
\hline 12 & Cerro Gordo, Ej. La Peña, mpio. de Aldama Tam. & & \\
\hline 16 & Ej. Vista Hermosa, carretera Soto La Marina - La Pesca & $23^{\circ} 48^{\prime \prime} 31^{\prime \prime}$ & $97^{\circ} 56^{\prime} 33^{\prime \prime}$ \\
\hline 17 & Carretera La Pesca - Soto La Marina después del entronque al Capote & $23^{\circ} 47^{\prime} 51^{\prime \prime}$ & $98^{\circ} 04^{\prime} 07^{\prime \prime}$ \\
\hline 18 & Soto la Marina, Tamaulipas & $23^{\circ} 44^{\prime} 54^{\prime \prime}$ & $98^{\circ} 12^{\prime} 45^{\prime \prime}$ \\
\hline 19 & Ej. El Sabinito km 97 Carretera Victoria - Soto La Marina, derecha de la carretera & $23^{\circ} 35^{\prime} 34^{\prime \prime}$ & $98^{\circ} 21^{\prime} 22^{\prime \prime}$ \\
\hline 20 & Rancho los Ebanos, Carretera Tepehuajes - San José de las Rusias & $23^{\circ} 30^{\prime} 00^{\prime \prime}$ & $97^{\circ} 49^{\prime} 18^{\prime \prime}$ \\
\hline 21 & Después del vado El Moro, carr. Victoria-Soto La Marina, km 69 & $23^{\circ} 35^{\prime} 14^{\prime}$, & $98^{\circ} 37^{\prime} 34^{\prime \prime}$ \\
\hline 22 & Ejido La Lajilla, al sureste de Casas & $23^{\circ} 38^{\prime} 15^{\prime \prime}$ & $98^{\circ} 33^{\prime} 26^{\prime}$ \\
\hline 23 & Villa de Casas & $23^{\circ} 42^{\prime} 37^{\prime}$ & $98^{\circ} 43^{\prime} 47^{\prime}$ \\
\hline 24 & Rancho La Palma, km 80, después de El Pirulí, desviación al Ejido Felipe Ángeles & $23^{\circ} 31^{\prime} 57^{\prime}$, & $98^{\circ} 31^{\prime} 22^{\prime \prime}$ \\
\hline
\end{tabular}

